\title{
Article \\ Influence of hard, artificial grass and clay court surfaces on wheelchair tennis players' mobility-a case study
}

\author{
Alejandro Sánchez-Pay ${ }^{1, *}$ and David Sanz-Rivas ${ }^{\mathbf{2}}$ \\ Received: $1^{\text {st }}$ January 2020; Accepted: $10^{\text {th }}$ December 2020; Published: 16 $6^{\text {th }}$ May 2021
}

\begin{abstract}
Wheelchair mobility is an important factor for success in wheelchair tennis. Tennis matches can be played on different surfaces, so the aim of the present study was to analyse the influence of court surface on wheelchair tennis mobility. Four male wheelchair tennis players (age $=33.75 \pm 12.33$ years) performed two tests (20 m sprint and agility t-test) on three official court surfaces (hard, artificial grass and clay). Photocell gates were used to record time and ascertain sprint and turn ability of the wheelchair tennis players. ANOVA test with post hoc pairwise comparisons were conducted to compare the mean differences among surfaces. Following the analysis, the wheelchair tennis players moved faster on hard or clay surfaces than on artificial grass although no statistically significant differences in the $20 \mathrm{~m}$ sprint and agility t-test between each of the three surfaces were found ( $\mathrm{p}$ $>$ 0.05). Moreover, the surface seems to affect mobility more, with respect to turns than in linear locomotion, although more research is needed on this aspect. The playing surfaces may need to be an extra variable in planning performance related activities such as techniques and tactics.
\end{abstract}

Keywords: biomechanics; movement; adapted sports; agility

\section{Introduction}

The Paralympic movement has had significant growth with an increasing number of countries and athletes participating in these games (Bernardi et al., 2010). Wheelchair sport, especially in ball games such as wheelchair basketball, wheelchair rugby and wheelchair tennis, are now an organised leisure-time activity as well as a competitive sport and has gained popularity (Abel, Platen, Rojas Vega, Schneider, \& Strüder, 2008). Wheelchair tennis (WT) is one of the public's favourite Paralympic sports (Diaper \& Goosey-Tolfrey, 2009). WT matches are always played to the best of three sets and the main difference regarding regulations in comparison to conventional tennis (CT) is that the ball can bounce twice before it must be returned (ITF, 2020). Currently, WT can be played on three surfaces (hard, grass and clay). There are some studies in WT that show the influence of surface on match statistics (Sánchez-Pay, Palao, Torres-Luque, \& Sanz-Rivas, 2015) or physical demands (Ponzano \& Gollin, 2017), but there are no studies on the influence of surface on WT mobility.

Wheelchair mobility is an important factor for success in WT (Bullock \& Pluim, 2003). Optimising mobility performance in wheelchair tennis is dependent on a combination of factors associated with the user, the wheelchair and the interface between both (Mason, van der Woude, \& Goosey-Tolfrey, 2013). Movement enables the player to adequately prepare him or herself for a stroke and to execute the maximum number of strokes (Filipčič \& Filipčič, 2009).

The movement dynamics of WT are specifically related to propelling the wheelchair while holding a tennis racket (Goosey-Tolfrey \& Moss, 2005). The specific movements of the WT players can include as sequence of starting, sprinting, braking, and turning (Sanz, 2003). 
Movement during a competitive WC tennis match is intermittent, multidirectional and nonrandom, which challenges the participant to change direction many times (Roy, Menear, Schmid, Hunter, \& Malone, 2006), so the ability to accelerate quickly from a standstill is considered more important than sprinting (Vanlandewijck, Theisen, \& Daly, 2001). WT players need to maintain the inertia of the chair for greater performance (Coutts, 1990), but the specific movement of the players includes turns (Sanz, 2003) and the changes in the inertia are more pronounced the faster they turn (Caspall, Seligsohn, Dao, \& Sprigle, 2013). For that reason, the most effective propulsion strategy would result in obtaining maximum velocities with the least amount of pushes as possible (Goosey-Tolfrey \& Moss, 2005). The maximum velocity a player can reach as well as the peak velocities reached in each of the first three pushes are restricted due to the presence of a racket (Goosey-Tolfrey \& Moss, 2005). Moreover, propelling the wheelchair while holding a racket has a negative influence on the velocity of movement (Sánchez-Pay \& Sanz-Rivas, 2018). This may be due to the propulsion technique and could lead to injuries in the upper limb (De Groot, Bos, Koopman, Hoekstra, \& Vegter, 2017). This could be because a longer time is needed to couple the hand with the racket and to the rim leads to higher power losses and subsequently higher power output generation during the shorter push phase (De Groot et al., 2017). This situation should be considered by coaches. Most studies on the biomechanics of locomotion in WT have been done in the laboratory or on just one playing surface. Nowadays, WT can be played on three surfaces (hard, grass and clay). No studies have been found on the influence of court surface on WT mobility, but it is hypothesised that the playing surface can influence it. Therefore, the aim of the present study was to analyse the influence of court surface on WT mobility.

\section{Materials and Methods}

\section{Participants}

Four male WT players (age $=33.75 \pm 12.33$ years) volunteered to participate in this study. Each player used their own sports wheelchair and racket. All players were righthanded and their characteristics can be found in Table 1. No additional injuries that could affect testing were reported. The study was conducted according to the Declaration of Helsinki and approved by the Bioethics Commission of the Murcia University and the National Tennis Federation. All participants were informed about the purpose and experimental procedures and signed a written informed consent form.

Table 1. Characteristics of the male wheelchair tennis players

\begin{tabular}{cccccccc}
\hline $\mathrm{n}$ & $\begin{array}{c}\text { ITF } \\
\text { ranking }\end{array}$ & $\begin{array}{c}\text { National } \\
\text { ranking }\end{array}$ & $\begin{array}{c}\text { Years of } \\
\text { training }\end{array}$ & Injury & Age & Height & $\begin{array}{c}\text { Year since } \\
\text { injury }\end{array}$ \\
\hline 1 & Top 40 & 3 & 6 & SCI L2* & 36 & 1.74 & 15 \\
2 & Top 200 & 10 & 9 & SCI D4* & 33 & 1.88 & 16 \\
3 & s/n & 40 & 2 & SCI D6 & 18 & 1.85 & 2 \\
4 & s/n & s/n & 8 & SCI D6 & 48 & 1.75 & 13 \\
\hline
\end{tabular}

SCI: Spinal Cord Injury. * Incomplete

\section{Procedure}

Participants were tested on one day. The WT field tests used are reliable and valid tests to measure the wheelchair mobility performance of WT players (Rietveld et al., 2019; Yanci et al., 2015). Participants had standardised rest times between the different tests. The order of the tests as well as the rest times are shown in Table 2. Furthermore, the tyre pressures in their chairs were checked and were similar among trials. It took approximately 90 minutes to test all the players with the complete test battery. The tests were performed on official court surfaces (hard, artificial grass and clay). A few days before the tests, specific exercises were performed to familiarise participants with the correct execution of the tests (sprint, ability and hand dynamometer test). The players were instructed to perform all tests at maximum intensity. No strenuous exercises were performed within the $48 \mathrm{~h}$ immediately 
prior to the tests and two researchers supervised the study at all times. Testing was conducted with each participant using their personal sports wheelchair.

In addition, the researchers divided the players into 3 levels (high, medium and lowlevel) depending on the average speed they could develop in a $20 \mathrm{~m}$ test on all surfaces. Thus, the high-level player averaged 6.259 s, medium-level players averaged $7.474 \mathrm{~s}$, and low-level player averaged $9.924 \mathrm{~s}$. Thus, medium-level players were $19.40 \%$ slower than the highlevel player and $19.39 \%$ faster than the low-level player. So, the performance differences between levels are similar.

Table 2. Schedule day test

\begin{tabular}{|c|c|c|c|c|}
\hline Court & & Har & Court & \\
\hline Test & Handgrip test & $20 \mathrm{~m}$ sprint test & T-test & Handgrip test \\
\hline Tries and resting time & 2 attempts ( 2 min rest) & 2 attempts ( 2 min rest) & 2 attempts ( 3 min rest) & 2 attempts (2 min rest) \\
\hline Change surface & \multicolumn{4}{|c|}{ Resting time: $25 \mathrm{~min}$} \\
\hline Court & \multicolumn{4}{|c|}{ Artificial Grass Court } \\
\hline Test & Handgrip test & $20 \mathrm{~m}$ sprint test & T-test & Handgrip test \\
\hline Tries and resting time & 2 attempts (2 min rest) & 2 attempts ( 2 min rest) & 2 attempts ( 3 min rest) & 2 attempts ( 2 min rest) \\
\hline Change surface & \multicolumn{4}{|c|}{ Resting time: $25 \mathrm{~min}$} \\
\hline Court & \multicolumn{4}{|c|}{ Clay Court } \\
\hline Test & Handgrip test & $20 \mathrm{~m}$ sprint test & T-test & Handgrip test \\
\hline Tries and resting time & 2 attempts (2 min rest) & 2 attempts ( 2 min rest) & 2 attempts ( 3 min rest) & 2 attempts (2 min rest) \\
\hline
\end{tabular}

\section{Wheelchair tennis field tests}

\section{0-m sprint}

The participant started from a stationary position, with the front wheels behind the "safety line" (0.5 m before the start line). The players performed a wheelchair sprint test consisting of two maximal sprints of $20 \mathrm{~m}$ as quickly as possible holding their own racket, with a 120 s rest period between each sprint, with enough time to return to the start and wait for their next turn (Yanci et al., 2015). The test is performed twice, and the end score is the best time of the two trials. Time was recorded using five photocell gates (Chronojump ${ }^{\circledR}$, Barcelona, Spain) and Chronojump 1.7.1.8 software version for MAC with an accuracy of \pm $0.001 \mathrm{~s}$. The timer was activated automatically as the player passed the first gate at the 0.0 $\mathrm{m}$ mark and split times were then recorded at 5, 10, 15 and $20 \mathrm{~m}$ (Figure 1). The sensors of the photocell gates were set $0.65 \mathrm{~m}$ above the ground, at the same height as the players' knees.

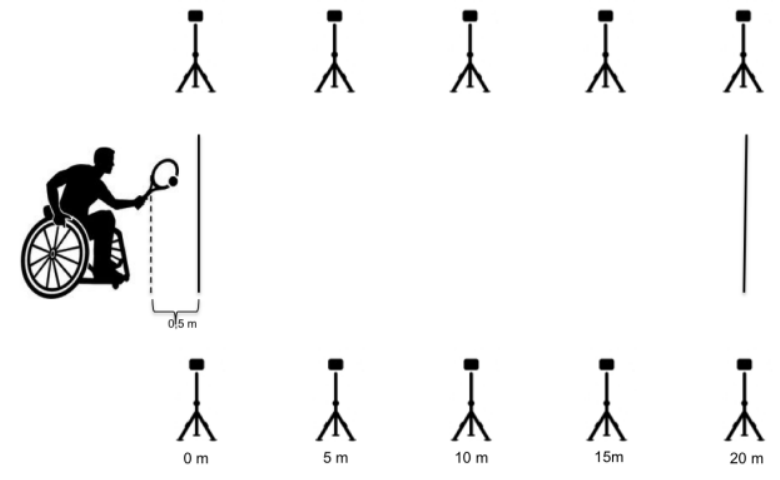

Figure 1. 20 metres wheelchair tennis test. Adapted from Sánchez-Pay \& Sanz-Rivas, 2019. Reprinted with permission. 


\section{Agility t-test}

The participant started from a stationary position, with the front wheels behind the "safety line" (0.5 m before the baseline). Players completed the circuit as follows (Figure 2) using the protocol (Yanci et al., 2015), modified to perform on a tennis court used in previous research (Sánchez-Pay \& Sanz-Rivas, 2019). Stage 1: each player moved quickly forward to the centre cone (1) passing on the left of the cone and turned to the right. Stage 2: player moved to the right cone (2), passing on the right of the cone and turned to the left. Stage 3: player moved to the left cone (3), passing to the right of the centre cone (2). Stage 4: player passed to the left cone (3) and turned to the right. Stage 5: player passed to the left of the centre cone (1) and turned to the right to finish crossing the baseline. All participants performed the test 2 times with at least 3 min rest between trials. The height of the cones was $0.3 \mathrm{~m}$. Time was recorded using three photocell gates (Chronojump ${ }^{\circledR}$, Barcelona, Spain) and Chronojump 1.7.1.8 software version for MAC with an accuracy of $\pm 0.001 \mathrm{~s}$. The timer was activated automatically as the player passed the first gate at the $0.0 \mathrm{~m}$ mark and split times were then recorded for each stage. The first gate was place on the baseline. The gates on court were placed at $2.5 \mathrm{~m}$ in a single line leaving enough distance for turning the wheelchair. The sensors of the photocell gates were set $0.65 \mathrm{~m}$ above the ground. In this way, the gates were positioned at the same height as the players' knees.

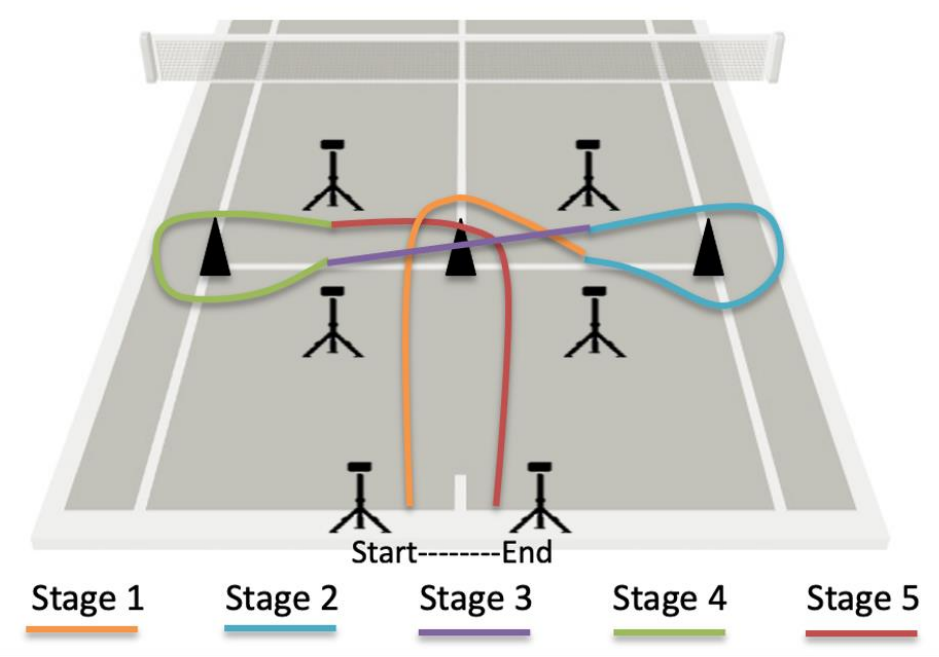

Figure 2. Stages of the agility wheelchair tennis test. Adapted from Sánchez-Pay \& Sanz-Rivas, 2019. Reprinted with permission.

\section{Handgrip}

The ability to transmit force to the chair depends heavily on the press (specific action to grab the ring and racket) (De Groot et al., 2017). For that reason, handgrip strength was measured in the dominant and non-dominant hand to monitor localised fatigue. Players performed the test seated in their wheelchair with the test arm fully extended in the vertical axis and not touching the wheelchair (Yanci et al., 2015). A portable hand dynamometer Smedley III T-18A (Takei, Tokyo, Japan) was used for handgrip strength measurement. The hand dynamometer has a range between 0 and $100 \mathrm{~kg}$ with $0.5 \mathrm{~kg}$ increments and an accuracy of $\pm 2 \mathrm{~kg}$. The test was done after a change of surface. After a phase of familiarisation with the instrument with sub-maximum repetitions, each subject made two attempts at maximum isometric contractions for $5 \mathrm{~s}$ with each hand. Rest time between each attempt was $2 \mathrm{~min}$. The best value of the two attempts was recorded in $\mathrm{Kg}$.

\section{Statistical analysis}

Data analysis was conducted using IBM SPSS version 20.0 (IBM Corp., Armonk, NY, USA). Descriptive statistics (mean, s.d.) were obtained. The Shapiro-Wilk and Levene tests 
were used to confirm the normality and homogeneity of variance, respectively. Coefficient of variation (CV): (SD/mean)* 100 was used to assess $20 \mathrm{~m}$ sprint, agility t-test and handgrip strength tests. A repeated measures ANOVA was used to show differences in hand dynamometry (pre-, post-tests) throughout the test session, and Pearson's correlation was used to show the distribution. An ANOVA test with post hoc pairwise comparisons was conducted to compare the mean differences (time as a dependent variable) among surfaces (as an independent variable). Effect sizes (d) were estimated by calculating Cohen's d. Effect sizes were interpreted as follows: trivial (0-0.2), small (0.2-0.5), moderate (0.50-1.0), and large (> 1.0) (Cohen, 1992). Wheelchair velocity was calculated (distance / time) for each stage (0-5 m, 5-10 m, 10-15 m, and 15-20 m) of the $20 \mathrm{~m}$ test. Additionally, the percentage of difference in speed between the sections of each level was calculated. The level of significance was set at $\mathrm{p}<.05$.

\section{Results}

The hand dynamometry test did not show statistically significant differences between pre-, post-tests on each surface (dominant $\mathrm{p}=.964$; non-dominant $\mathrm{p}=.434$ ). The dominant hand did not show a high correlation throughout the 6 tests developed. The non-dominant hand showed a medium correlation $\left(\mathrm{r}^{2}=0.48\right)$ increasing the force values from the beginning to the end of the tests. The CV of the hand dynamometry test was $4.87 \%$ (Figure 3).

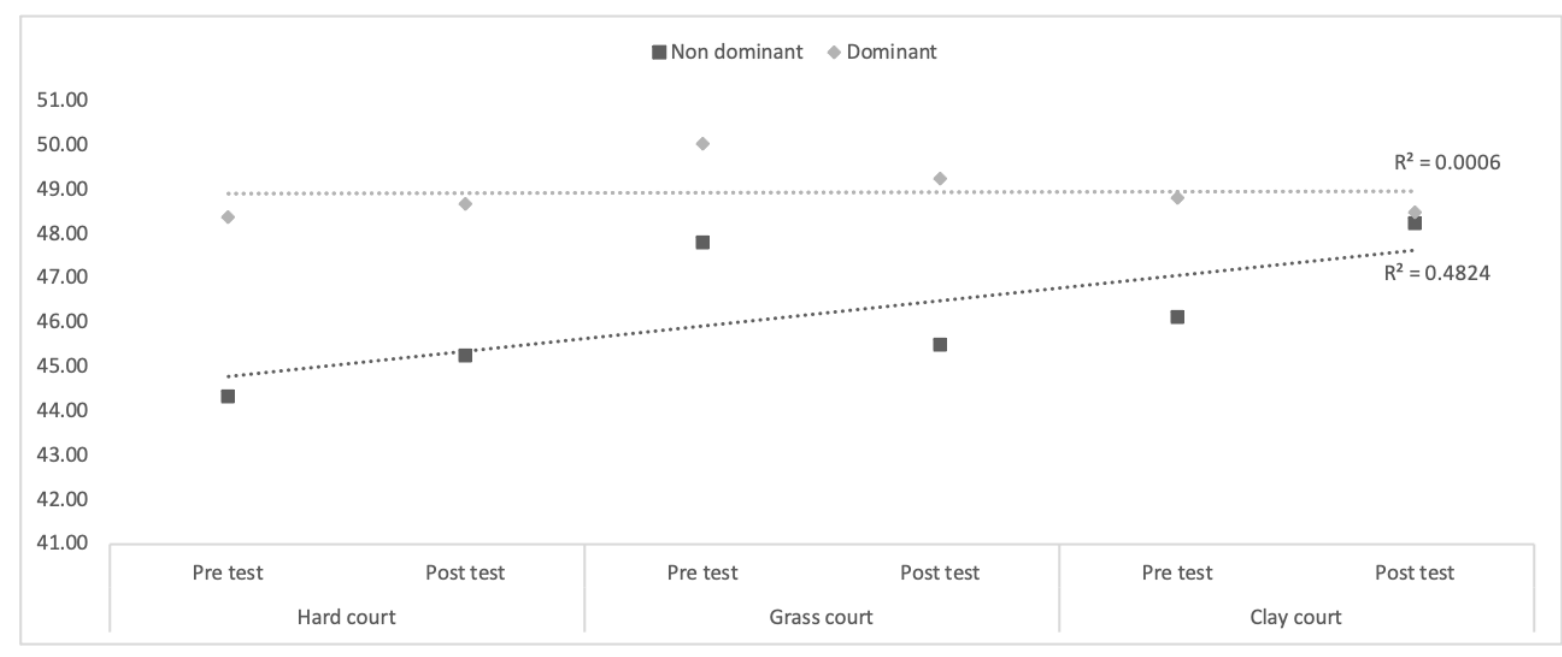

Figure 3. Hand dynamometry results during the wheelchair tennis test day

There were no statistically significant differences found in the $20 \mathrm{~m}$ test between each of the three surfaces (Table 3). There was a statistically significant difference in stage $4(\mathrm{p}=$ .045) of the agility t-test (Table 4); but post hoc comparisons were not statistically significant between the hard and artificial grass surface $(\mathrm{p}=.075 ; \mathrm{d}=1.78)$ or the clay and grass surface $(\mathrm{p}=.065 ; \mathrm{d}=1.86)$. The CV of the $20 \mathrm{~m}$ and t-test test was $2.54 \%$ and $0.48 \%$ on the hard surface, $5.60 \%$ and $1.47 \%$ on the clay surface, and $5.97 \%$ and $0.73 \%$ on the artificial grass surface.

Percentual differences (\%) between $0-5 \mathrm{~m}$ and $15-20 \mathrm{~m}$ wheelchair velocity $(\mathrm{m} \cdot \mathrm{s}-1)$ by level and surface it is show in Figure 4. The high-level player showed the greatest differences between the first and fourth stage on the hard $\left(1.40 \mathrm{~m} \cdot \mathrm{s}^{-1}\right)$ and clay surface $\left(1.73 \mathrm{~m} \cdot \mathrm{s}^{-1}\right)$. The medium-level players showed similar differences between stages on the hard $\left(0.37 \mathrm{~m} \cdot \mathrm{s}^{-1}\right)$, clay $\left(0.76 \mathrm{~m} \cdot \mathrm{s}^{-1}\right)$ and artificial grass surfaces $\left(0.51 \mathrm{~m} \cdot \mathrm{s}^{-1}\right)$. The low-level player also showed similar differences between stages on the hard $\left(0.58 \mathrm{~m} \cdot \mathrm{s}^{-1}\right)$ and clay $\left(0.51 \mathrm{~m} \cdot \mathrm{s}^{-1}\right)$ surfaces although on the artificial grass surface the difference was lower $\left(0.10 \mathrm{~m} \cdot \mathrm{s}^{-1}\right)$. In addition, all players lost speed in the last stage with respect to the third stage on the artificial grass court 
$\left(-0.12 \mathrm{~m} \cdot \mathrm{s}^{-1}\right.$ in the high-level player; $-0.29 \mathrm{~m} \cdot \mathrm{s}^{-1}$ in medium-level players; and $-0.01 \mathrm{~m} \cdot \mathrm{s}^{-1}$ in the low-level player).

Table 3. Mean (M), standard deviation (SD) in seconds, statistical differences (p) and effect sizes (d) of the time spent in the $20 \mathrm{~m}$ sprint test.

\begin{tabular}{|c|c|c|c|c|c|c|c|c|}
\hline & \multirow{2}{*}{$\begin{array}{c}\text { Hard } \\
\mathrm{M} \\
(\mathrm{SD})\end{array}$} & \multirow{2}{*}{$\begin{array}{c}\text { Clay } \\
\mathrm{M} \\
\text { (SD) } \\
\end{array}$} & \multirow{2}{*}{$\begin{array}{c}\text { Grass } \\
\mathrm{M} \\
(\mathrm{SD}) \\
\end{array}$} & \multirow[b]{2}{*}{$\mathrm{F}$} & \multirow[b]{2}{*}{$\begin{array}{c}\mathrm{p} \\
\text { value }\end{array}$} & \multicolumn{3}{|c|}{ Effect sizes d ( $\pm 95 \% \mathrm{CI})$} \\
\hline & & & & & & Hard vs. Clay & $\begin{array}{l}\text { Hard vs. } \\
\text { Grass }\end{array}$ & $\begin{array}{c}\text { Clay vs. } \\
\text { Grass }\end{array}$ \\
\hline $0-5 \mathrm{~m}$ & $2.028(0.13)$ & $2.289(0.31)$ & $2.287(0.24)$ & 0.615 & .562 & $\begin{array}{c}0.68 \\
(-2.32 ; 0.95)\end{array}$ & $\begin{array}{c}0.67 \\
(2.31 ; 0.96)\end{array}$ & $\begin{array}{c}0.01 \\
(-1.59 ; 1.60)\end{array}$ \\
\hline $5-10 \mathrm{~m}$ & $1.714(0.23)$ & $1.743(0.32)$ & $1.863(0.27)$ & 0.274 & .767 & $\begin{array}{c}0.05 \\
(-1.65 ; 1.55)\end{array}$ & $\begin{array}{c}0.47 \\
(-2.10 ; 1.14)\end{array}$ & $\begin{array}{c}0.42 \\
(-2.04 ; 1.19)\end{array}$ \\
\hline $10-15 \mathrm{~m}$ & $1.63(0.25)$ & $1.665(0.32)$ & $1.889(0.36)$ & 0.673 & .534 & $\begin{array}{c}0.02 \\
(-1.63 ; 1.57)\end{array}$ & $\begin{array}{c}0.72 \\
(-2.37 ; 0.92)\end{array}$ & $\begin{array}{c}0.69 \\
(-2.34 ; 0.94)\end{array}$ \\
\hline $15-20 \mathrm{~m}$ & $1.838(0.51)$ & $1.675(0.43)$ & $1.999(0.28)$ & 1.043 & .391 & $\begin{array}{c}0.05 \\
(-1.55 ; 1.65)\end{array}$ & $\begin{array}{c}0.85 \\
(-2.52 ; 0.80)\end{array}$ & $\begin{array}{c}0.91 \\
(-2.58 ; 0.76)\end{array}$ \\
\hline Total & $7.21(1.05)$ & $7.371(1.34)$ & $8.038(1.07)$ & 0.596 & .571 & $\begin{array}{c}0.15 \\
(-1.76 ; 1.44)\end{array}$ & $\begin{array}{c}0.73 \\
(-2.38 ; 0.91)\end{array}$ & $\begin{array}{c}0.57 \\
(-2.21 ; 1.05)\end{array}$ \\
\hline
\end{tabular}

Table 4. Mean (M), standard deviation (SD) in seconds, statistical differences (p) and effect sizes (d) of the time spent in the agility t-test.

\begin{tabular}{|c|c|c|c|c|c|c|c|c|}
\hline & \multirow{2}{*}{$\begin{array}{c}\text { Hard } \\
\mathrm{M}(\mathrm{SD})\end{array}$} & \multirow{2}{*}{$\begin{array}{c}\text { Clay } \\
\text { M (SD) }\end{array}$} & \multirow{2}{*}{$\begin{array}{c}\text { Grass } \\
\text { M (SD) }\end{array}$} & \multirow[b]{2}{*}{$\mathrm{F}$} & \multirow[b]{2}{*}{$\begin{array}{c}\mathrm{p} \\
\text { value }\end{array}$} & \multicolumn{3}{|c|}{ Effect sizes d $( \pm 95 \%$ CI $)$} \\
\hline & & & & & & Hard vs. Clay & $\begin{array}{c}\text { Hard vs. } \\
\text { Grass }\end{array}$ & $\begin{array}{c}\text { Clay vs. } \\
\text { Grass }\end{array}$ \\
\hline Stage 1 & $3.743(0.55)$ & $4.3(0.56)$ & $3.887(0.58)$ & 1.055 & .388 & $\begin{array}{c}0.98 \\
(-2.67 ; 0.69)\end{array}$ & $\begin{array}{c}0.25 \\
(-1.86 ; 1.35)\end{array}$ & $\begin{array}{c}0.73 \\
(-0.91 ; 2.38)\end{array}$ \\
\hline Stage 2 & $3.427(0.46)$ & $3.508(0.32)$ & $3.96(0.72)$ & 1.189 & .348 & $\begin{array}{c}0.15 \\
(-1.76 ; 1.44)\end{array}$ & $\begin{array}{c}1.01 \\
(-2.70 ; 0.76)\end{array}$ & $\begin{array}{c}0.85 \\
(-2.52 ; 0.80)\end{array}$ \\
\hline Stage 3 & $1.26(0.14)$ & $1.738(0.28)$ & $1.554(0.39)$ & 2.839 & .111 & $\begin{array}{c}1.67 \\
(-3.50 ; 0.16)\end{array}$ & $\begin{array}{c}1.02 \\
(-2.71 ; 0.66)\end{array}$ & $\begin{array}{c}0.64 \\
(-0.99 ; 2.27)\end{array}$ \\
\hline Stage 4 & $3.301(0.35)$ & $3.273(0.25)$ & $3.977(0.49)$ & 4.452 & .045 & $\begin{array}{c}0.07 \\
(-1.53 ; 1.67)\end{array}$ & $\begin{array}{c}1.78 \\
(-3.65 ; 0.07)\end{array}$ & $\begin{array}{c}1.86 \\
(-3.75 ; 0.02)\end{array}$ \\
\hline Stage 5 & $3.618(0.61)$ & $3.989(0.65)$ & $4.169(0.89)$ & 0.593 & .573 & $\begin{array}{c}0.50 \\
(-2.13 ; 1.11)\end{array}$ & $\begin{array}{c}0.75 \\
(-2.40 ; 0.89)\end{array}$ & $\begin{array}{c}0.24 \\
(-1.85 ; 1.35)\end{array}$ \\
\hline Total & $15.348(2.06)$ & $16.808(1.99)$ & $17.546(3.01)$ & 0.869 & .452 & $\begin{array}{c}0.60 \\
(-2.24 ; 1.02)\end{array}$ & $\begin{array}{c}0.91 \\
(-2.59 ; 0.75)\end{array}$ & $\begin{array}{c}0.30 \\
(-1.92 ; 1.30) \\
\end{array}$ \\
\hline
\end{tabular}

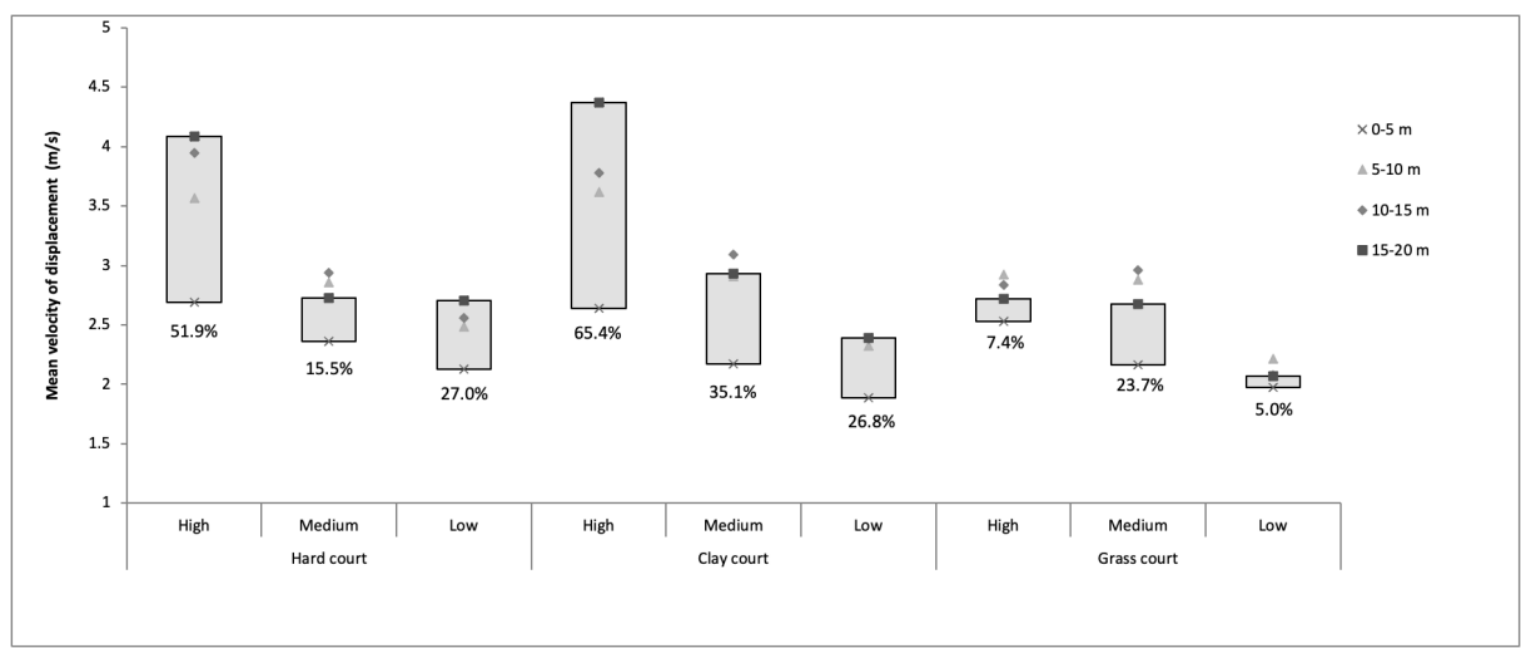

Figure 4. Differences of wheelchair velocity in the $20 \mathrm{~m}$ sprint test by level, surfaces and stages

\section{Discussion}

To our knowledge, this is the first study to analyse the influence of court surface on wheelchair tennis mobility. Knowledge of players' mobility helps to improve training methods. Although there are no statistically significant differences between surfaces, 
wheelchair tennis players were faster on hard courts than other surfaces. The players seem to be able to increase their speed up to $15 \mathrm{~m}$ on hard and clay surfaces, and up to $10 \mathrm{~m}$ on grass. From there, the players began to lose speed, and are not able to maintain the acceleration ability achieved during the first meters. Normally, WT players cover 6 metres in a rally (Filipčič \& Filipčič, 2009) hitting the ball 3-4 times per point (Sánchez-Pay, SanzRivas, \& Torres-Luque, 2015), so the movement is over short distances between shots. This activity pattern shows that ability to accelerate quickly from a standstill is considered more important than sprinting (Vanlandewijck et al., 2001), and the decrease in speed after 10 metres does not have to be a limiting factor of performance for the WT players.

The specific movements of the WT players can include as sequence of starting, sprinting, braking, and turning (Sanz, 2003). The agility t-test has been used in several studies to measure acceleration, braking and turning capacity in wheelchair basketball (Yanci et al., 2015) or wheelchair tennis (Sánchez-Pay \& Sanz-Rivas, 2019). The results show no statistically significant differences in the total result of the test although players moved 14.3 \% slower on artificial grass and $9.5 \%$ on clay compared to a hard surface. Statistically significant differences were found in the agility t-test just in stage 4 (when the players turn to the right). This turn is made by the player with the hand that holds the racket. There are researchers who reported the influence of the use of the racket on the linear movement (De Groot et al., 2017; Sánchez-Pay \& Sanz-Rivas, 2018). The results in this study seem to indicate that the turn could be affected to a greater extent when comparing surfaces $(\approx 20-$ $22 \%$ lower on grass than hard or clay surfaces respectively).

In relation to the court pace rating, tennis regulations differentiate the following types of surface: 1 (slow pace), 2 (medium-slow pace), 3 (medium pace), 4 (medium-fast pace), and 5 (fast pace) (ITF, 2020). In this case, our clay court is classified as type 1 (slow pace), the hard court as type 3 (medium pace) and the artificial grass court as type 4 (medium-fast pace). WT players can move faster on hard or clay surfaces than artificial grass. In linear locomotion, WT players move slower on grass $(11.7 \%)$ or clay $(2.5 \%)$ than on a hard court. When players move like in a rally (mobility with turns) the differences were greater, moved slower on artificial grass (14.3\%) or clay (9.5\%) than on a hard court. In this respect, it is plausible to consider the hard and clay surfaces do not have the same relation to the speed of linear locomotion in WT as they do in the running of conventional tennis players on clay and carpet courts (Ferrauti, Fernandez-Fernandez, Klapsing, Ulbricht, \& Rosenkranz, 2013).

Comparing the ability to accelerate and maintain inertia for players of different levels, the higher-level player moved faster than medium or low-level players. This may seem obvious because the tests have construct validity that discriminated between levels (Yanci et al., 2015; Rietveld et al., 2019). For the higher-level player, the differences between 5 and 20 $\mathrm{m}$ are greater on hard and clay surfaces (59.9-65.4\%) than on artificial grass (7.4\%). On the contrary, for players of medium or low-level the range of values are similar on all the surfaces (5-27\%).

Given the results obtained it could be confirmed that wheelchair tennis players move slower on artificial grass and on clay than on hard court, and this is especially important on the specific turn movements (inside and outside turns). As a case study, our research has some limitations. An important limitation is the sample size, so the data presented here cannot be generalised. This may be one of the reasons why, despite finding differences between the surfaces in absolute values, these are not statistically significant. There are some studies of the influence of level of impairment on wheelchair velocity; for that reason, it would be interesting in future research to consider the influence of surface on wheelchair velocity in players with different levels of impairment. In addition, the use of new devices such as inertial measurement units, could be a viable option to accurately monitor temporal parameters of wheelchair propulsion, such as stroke number and push frequency (Lewis et al., 2018) that could be different depending on the playing surface.

\section{Perspectives}


In this case study, the surface seems to affect mobility more in turns than in linear locomotion. Moreover, surface seems to influence acceleration capacity differently, and the ability to maintain the inertia of the wheelchair is different depending on the level of players. From our knowledge, after the results found, we encourage players to train according to the kind of surface they will have to play on because the number of linear movements is few, but the number of turns is really high, not only going forward to hit the ball but also to subsequently recover position (inside and outside turns). This is especially crucial for competitive WT players.

Although more research is needed on this topic, coaches could begin to use this information as a guide on the training of mobility in WT players according to the surface, in order to adapt not only the drills but also the times they have between strokes, to allow the player to recover the correct position. In this respect, we recommend training before competing on the same surface to adapt mobility, and also to train the three first pushes on the wheel because they are crucial for gaining speed.

Moreover, in this specific modality of tennis, we should take into account the tyre, and in order to reduce the inertia on clay and on grass, given these results, we would encourage the players to modify the pressure in their tyres for these kinds of surfaces.

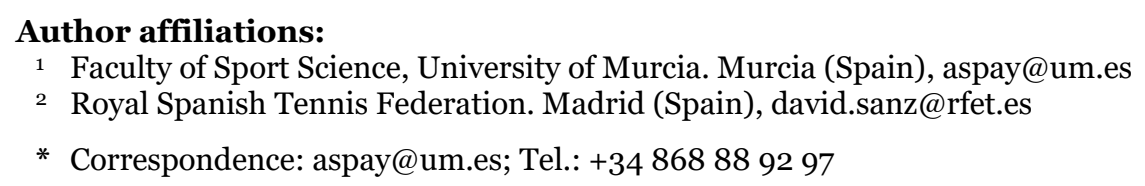

Author Contributions: Conceptualization, ASP \& DSR; Methodology, ASP \& DSR; Formal Analysis, ASP; Writing-Original Draft Preparation, ASP; Writing-Review \& Editing, ASP \& DSR.

Funding: This research received no external funding

Acknowledgments: We are grateful for the cooperation of the wheelchair tennis players. In addition, we thank La Manga Club for providing the tennis courts.

Conflicts of Interest: The authors declare no conflict of interest.

\section{References}

Abel, T., Platen, P., Rojas Vega, S., Schneider, S., \& Strüder, H. K. (2008). Energy expenditure in ball games for wheelchair users. Spinal Cord, 46(12), 785-790. https://doi.org/10.1038/sc.2008.54

Bernardi, M., Guerra, E., Di Giacinto, B., Di Cesare, A., Castellano, V., \& Bhambhani, Y. (2010). Field evaluation of paralympic athletes in selected sports: Implications for training. Medicine and Science in Sports and Exercise, 42(6), 1200-1208. https://doi.org/10.1249/MSS.obo13e3181c67d82

Bullock, M., \& Pluim, B. (2003). Wheelchair tennis and physical conditioning. ITF Wheelchair Tennis Coaches Review, 3(9), 2-10.

Caspall, J. J., Seligsohn, E., Dao, P. V., \& Sprigle, S. (2013). Changes in inertia and effect on turning effort across different wheelchair configurations. Journal of Rehabilitation Research and Development, 50(10), 1353-1362. https://doi.org/10.1682/JRRD.2012.12.0219

Cohen, J. (1992). Statistical power analysis. Current Directions in Psychological Science, 1(3), 98-101. https://doi.org/10.1111/1467-8721.ep10768783

Coutts, K. D. (1990). Kinematics of sport wheelchair propulsion. Journal of Rehabilitation Research and Development, 27(1), 21-26. https://doi.org/10.1682/jrrd.1990.01.0021

De Groot, S., Bos, F., Koopman, J., Hoekstra, A. E., \& Vegter, R. J. K. (2017). Effect of holding a racket on propulsion technique of wheelchair tennis players. Scandinavian Journal of Medicine and Science in Sports, 27(9), 918-924. https://doi.org/10.1111/sms.12701

Diaper, N. J., \& Goosey-Tolfrey, V. L. (2009). A physiological case study of a paralympic wheelchair tennis player: Reflective practise. Journal of Sports Science and Medicine, 8(2), 300-307. https://www.ncbi.nlm.nih.gov/pmc/articles/PMC3761472/

Ferrauti, A., Fernandez-Fernandez, J., Klapsing, G. M., Ulbricht, A., \& Rosenkranz, D. (2013). Diagnostic of footwork characteristics and running speed demands in tennis on 
different ground surfaces. Sports Orthopaedics and Traumatology, 29(3), 172-179. https://doi.org/10.1016/j.orthtr.2013.07.017

Filipčič, T., \& Filipčič, A. (2009). Analysis of movement velocity and distance covered in wheelchair tennis. Kinesiologia Slovenica, 32, 25-32.

https://www.kinsi.si/mma/70741 184.pdf/201805221116280019/

Goosey-Tolfrey, V. L., \& Moss, A. D. (2005). Wheelchair velocity of tennis players during propulsion with and without the use of racquets. Adapted Physical Activity Quarterly, 22, 291-301. https://doi.org/10.1123/apaq.22.3.291

ITF. (2020). International Tennis Regulation. Regulations For Wheelchair Tennis 2020. Retrieved from https://www.itftennis.com/media/14.57/final-wheelchair-tennisregulations.pdf

Lewis, A. R., Haydon, D. S., Phillips, E. J., Grimshaw, P. N., Pinder, R. A., Winter, J., ... Portus, M. R. (2018). Placement effects of inertial measurement units on contact identification in wheelchair racing. Sports Biomechanics, 1-16. https://doi.org/10.1080/14763141.2018.1522367

Mason, B. S., van der Woude, L. H. V, \& Goosey-Tolfrey, V. L. (2013). The ergonomics of wheelchair configuration for optimal performance in the wheelchair court sports. Sports Medicine, 43, 23-38. https://doi.org/10.1007/s40279-012-0005-x

Ponzano, M., \& Gollin, M. (2017). Physical demand of wheelchair tennis match-play on hard courts and clay courts. International Journal of Performance Analysis in Sport, 17(4), 656-665. https://doi.org/10.1080/24748668.2017.1384975

Rietveld, T., Vegter, R. J. K., van der Slikke, R. M. A., Hoekstra, A. E., van der Woude, L. H. V, \& de Groot, S. (2019). Wheelchair mobility performance of elite wheelchair tennis players during four field tests: Inter-trial reliability and construct validity. PLOS ONE, 14(6), 1-16. https://doi.org/10.1371/journal.pone.0217514

Roy, J. L. P., Menear, K. S., Schmid, M. M. A, Hunter, G. R., \& Malone, L. A. (2006). Physiological responses of skilled players during a competitive wheelchair tennis match. Journal of Strength and Conditioning Research, 2O(3), 665-671. https://doi.org/10.1519/R-17845.1

Sánchez-Pay, A., Palao, J. M., Torres-Luque, G., \& Sanz-Rivas, D. (2015). Differences in set statistics between wheelchair and conventional tennis on different types of surfaces and by gender. International Journal of Performance Analysis in Sport, 15(3), 11771188. https://doi.org/10.1080/24748668.2015.11868860

Sánchez-Pay, A., \& Sanz-Rivas, D. (2018). Wheelchair tennis player movement speed: Differences in movement, with and without a racket. ITF Coaching and Sport Science Review, 76(26), 29-30.

https://www.itf-academy.com/?view=itfview\&academy=103\&itemid=1168

Sánchez-Pay, A., \& Sanz-Rivas, D. (2019). Assessment of the physical condition of the high-level wheelchair tennis player according to competitive level and kind of injury. RICYDE. Revista Internacional de Ciencias Del Deporte, 15(57), 235-248. https://doi.org/10.5232/ricyde2019.05702

Sánchez-Pay, A., Sanz-Rivas, D., \& Torres-Luque, G. (2015). Match analysis in a wheelchair tennis tournament. International Journal of Performance Analysis in Sport, 15(3), 540-550. https://doi.org/10.1080/24748668.2015.11868812

Sanz, D. (2003). Wheelchair tennis. Barcelona: Paidotribo.

Vanlandewijck, Y., Theisen, D., \& Daly, D. (2001). Wheelchair propulsion biomechanics: implications for wheelchair sports. Sports Medicine, 31(5), 339-367. https://doi.org/10.2165/00007256-200131050-00005

Yanci, J., Granados, C., Otero, M., Badiola, A., Olasagasti, J., Bidaurrazaga-Letona, I., ... Gil, S. M. (2015). Sprint, agility, strength and endurance capacity in wheelchair basketball players. Biology of Sport, 32(1):71-8. https://doi.org/10.5604/20831862.1127285

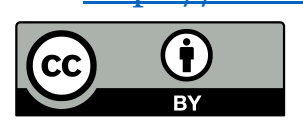

(c) 2021 by the authors. Submitted for possible open access publication under the terms and conditions of the Creative Commons Attribution (CC BY) license (http://creativecommons.org/licenses/by/4.0/). 